\title{
Memórias de Adriano e a ficção histórica
}

Noemi Perdigão ${ }^{1}$

\section{Resumo}

Este artigo trata da questão da relação entre história e literatura e terá como foco os dois capítulos finais do romance Memórias de Adriano, que apresentam e discutem a importância da história e da ficção na construção do romance. Paralelamente, são apresentadas de forma breve algumas posturas teóricas sobre a questão da ficção histórica.

Palavras-chave: Literatura. Ficção histórica.

\begin{abstract}
This paper addresses the issues related to the relationship between history and literature and focuses on the two final chapters of the novel Memoirs of Hadrian, which presents and discusses the importance of history and fiction in the novel's construction. Additionally, a few more theoretical positions on the theme of historical fiction are presented.
\end{abstract}

Keywords: Literature. Historical fiction.

(....) a história não é o registro transparente de nenhuma "verdade" indiscutível. Em vez disso, [a metaficção historiográfica] confirma as visões de historiadores como Dominick LaCapra que afirmam que "o passado chega na forma de textos e de vestígios textualizados - memórias, relatos, escritos publicados, arquivos, monumentos, etc" e que estes textos interagem de formas complexas.

Linda Hutcheon Poética do pós-modernismo : historia, teoria, ficção

À travers des destinées individuelles (c'est en cela qu'il est roman) exemplaires, le roman historique exprime les problèmes d'une époque donnée (c'est en cela qu'il est historique) du passé. Mais comment oublier, et faire oublier le présent ${ }^{[6]}$ ?

Scott met en scènes des personnages représentant chacun une classe sociale (des «types historico-sociaux ${ }^{[9]} »$ ), mais restant des individus dans la mesure où ils sont soumis à leurs passions. Quant aux événement et à la crise, ils sont en " interaction dialectique » avec les destins individuels pour mettre en évidence l'« essence » de l'époque (les causes, les effets et réactions des événements sur les différentes couches sociales).

Lukács, Georg. Le Roman historique.

\footnotetext{
${ }^{1}$ Mestrado em Letras pela Universidade Federal do Paraná, Brasil(1993). Doutoranda-UTFPR. E-mail: noemi@utfpr.edu.br
} 


\title{
Introdução
}

A questão do romance histórico tem constituído preocupação para diversos pensadores de diferentes épocas, desde Aristóteles, que entende o discurso literário como

\begin{abstract}
representação do verossímil e do necessário, ou seja, daquilo que poderia acontecer, independentemente de sua vinculação com uma 'verdade' exterior [...] e o poeta, como aquele que é capaz de organizar uma história plausível que, eventualmente, pode até conter o real. (GOBBI, 2004. p. 40 ).
\end{abstract}

Nesse sentido, Memórias de Adriano constitui um bom 'laboratório’ de análise, pois é fruto de uma exaustiva pesquisa histórica por parte da autora Marguerite Yourcenar, que, contudo, ao mesmo tempo, relativiza a ‘autoridade’ histórica:

Estratão de Sardes, poeta erótico e compilador do décimo segundo livro da Antologia, vivia provavelmente no tempo de Adriano; nada prova que ele tenha convivido com o imperador, mas me pareceu tentador promover o encontro desses dois homens. (YOURCENAR, 1980. p. 320).

É interessante percebermos que mesmo em uma obra que foi fruto de pesquisa extensa (sua primeira versão data de 1924, tendo sido publicada somente em 1951), a história aparece como leitura possível, não como a única autorizada.

Esta chave aparece subrepticiamente em toda a narrativa, mas de forma evidente no ‘Caderno de Notas’ e na 'Nota’ das Memórias de Adriano, dois últimos capítulos da obra.

Neste sentido, este ensaio terá como foco os dois capítulos finais do romance nos quais a autora nos apresenta o percurso e os percalços enfrentados quando da construção da narrativa. Paralelamente, serão apresentadas de forma breve algumas posturas teóricas sobre a questão da ficção histórica.

\section{Memórias de Adriano e o romance histórico}

Façamos o que fizermos, reconstruímos sempre o monumento à nossa maneira.

Mas já é muito não utilizar senão pedras autênticas.

Memórias de Adriano

O excerto abaixo resume de forma exemplar a postura que a autora apresenta como norteadora de sua ação na construção da obra: 
As regras do jogo: tudo aprender, tudo ler, informar-se de tudo e, simultaneamente, adaptar ao objetivo a ser atingido os 'Exercícios' de Inácio de Loyola ou o método do asceta hindu que se esgota, durante anos, para visualizar um pouco mais exatamente a imagem que ele criou sob suas pálpebras fechadas.[...] tentar restituir a mobilidade, a leveza do ser vivo a essas faces de pedra. (YOURCENAR, 1980. p. 302).

A pesquisa histórica existiu, foi exaustiva, mas Yourcenar deixa claro que não ficou refém das informações históricas para compor a obra. O dado histórico aparece integrado na intriga, compondo a trama das ações e figurando os planos ontológicos propostos por Paul Ricoeur (através de Fredric Jameson):

O primeiro, naturalmente, é o plano existencial da vida individual (e dos personagens da maioria das ficções). O segundo é o plano histórico e transindividual [...] o da relação do indivíduo com seus contemporâneos, bem como com as gerações anteriores e também, pode-se presumir, com as posteriores. (JAMESON, 2007, p. 190).

Além disso, ainda conforme a proposição de Ricoeur, para que um romance se torne histórico no sentido genérico, deve fundamentalmente narrar

um evento inaugural, que se considera o início de uma nova era - o nascimento de Cristo ou do Buda, a Hégira, o início do reino de um certo monarea [que] determina o momento axial em relação ao qual todos os outros eventos são datados.

(JAMESON, 2007, p. 191).

Memórias de Adriano figura diferentes momentos históricos (fim da era de Domiciniano, início da era de Trajano, as inúmeras guerras do período, a ascensão da cultura helênica, a importância de Roma como centro administrativo e político), mas se organiza em torno da assumpção de Adriano como imperador.

Queria o poder! Queria-o para impor meus planos, experimentar minhas soluções, restaurar a paz. Queria-o sobretudo para ser eu mesmo antes de morrer. [...] Uma calma extraordinária se apossou de mim: a ambição e o medo pareciam um pesadelo já esquecido. Sucedesse o que sucedesse, eu tinha estado desde sempre decidido a defender até o fim minhas possibilidades imperiais. $\mathrm{O}$ ato da adoção simplificava tudo. Minha própria vida já não me preocupava: podia novamente pensar no resto da humanidade. (YOURCENAR, 1980. p. 94-99).

Jameson desenvolve sua argumentação definindo o que entende por romance histórico:

O romance histórico não deve mostrar nem existências individuais nem acontecimentos históricos, mas a interseção de ambos. [...] A arte do romance histórico [consiste] na habilidade e engenhosidade com que a sua interseção é configurada e exprimida; e isso não é uma técnica nem uma forma, mas uma invenção singular, que precisa ser produzida de modo novo e inesperado em cada caso e que no mais das vezes não é passível de ser repetida. (JAMESON, 2007, p. 192). 
A maioria dos teóricos concorda em afirmar que a ficção histórica, romance histórico ou metaficção historiográfica, apesar de navegar entre os extremos da submissão ao referencial e os da ficcionalização radical das informações históricas, deve buscar a maestria de figurar a história no texto literário sem destruir a especificidade deste último enquanto objeto estético.

\begin{abstract}
Ao romance histórico não interessa repetir o relato dos grandes acontecimentos, mas ressuscitar poeticamente os seres humanos que viveram esta experiência. Ele deve fazer com que o leitor apreenda as razões sociais e humanas que fizeram com que os homens daquele tempo e daquele espaço pensassem, sentissem e agissem da forma como o fizeram. (WEINHARDT, 1994. p. 51).
\end{abstract}

Em Memórias de Adriano, é possível sentirmos ecos da vida em Roma e Atenas no século II, vivenciarmos a atmosfera de corrupção e revolta que cercavam Domiciano, as opções de Trajano por guerras de antemão perdidas, conhecermos Nerva e sobretudo Plotina, mulheres essenciais na definição do destino do império, partilharmos do desnudar-se de Adriano e com ele aprendermos os estratagemas para obter e manter o poder, sem vender suas convicções nem sua alma, porém todas estas informações compõem um todo esteticamente coerente, e Adriano narrador é um persongem complexo e contraditório, porque humano, assim como os demais personagens que nos são apresentados, em diferentes momentos e relações de sua vida:

Seria fácil dispor os dados precedentes como a história de um soldado demasiado letrado que pretende fazer-se perdoar pelos seus livros. Essas perspectivas simplificantes são falsas. Personagens diversas viviam em mim alternadamente [...] Minha versatilidade era-me necessária ; multiplicava-me por cálculo, era ondulante por jogo. Caminhava sobre a corda bamba. (YOURCENAR, 1980. p. 62; p. 68).

Na verdade, a maioria dos teóricos que têm se dedicado a refletir sobre esta questão aponta para a integração dialética entre ambas as instâncias (a história e a literatura), uma vez que constituem “um dado inalienável ao próprio fazer artístico”.(GOBBI, 2004, p. 37)².

Na verdade, o que se evidencia em Memórias de Adriano é a prevalência do literário sobre o histórico. A força da obra deriva sobretudo de sua coerência interna enquanto texto ficcional.

Perry Anderson, em artigo respondendo ao argumento de Fredric Jameson, ressalta a surpresa que foi o Goncourt atribuído a Memórias de Adriano em 1951, em função de a ficção histórica estar fora de moda. Ainda, qualifica a obra de “anomalia estranha,” sem aprofundar as razões de tal denominação. 
Talvez esta anomalia estranha de que fala Perry Anderson decorra da opção pela narração em $1^{\mathrm{a}}$ pessoa, algo inusitado em se tratando de uma obra ficcional fruto de extensa pesquisa histórica. Isso reforça o argumento da preponderância do ficcional sobre o histórico, pois Adriano narra para melhor se conhecer antes de morrer, postura que o aproxima de dois importantes narradores da literatura brasileira : Paulo Honório e Riobaldo: Ignoro a que conclusões esta narrativa me conduzirá. Conto com este exame dos
fatos para definir-me, para julgar-me talvez ou, quando muito, para melhor conhecer
a mim mesmo antes de morrer. (YOURCENAR, 1980. p. 30).

Tenciono contar a minha história. Difícil. Talvez deixe de mencionar particularidades úteis, que me pareçam acessórias e dispensáveis.Também pode ser que, habituado a tratar com matutos, não confie suficientemente na compreensão dos leitores e repita passagens insignificantes. (RAMOS, 1975. p. 10).

De primeiro, eu fazia e mexia, e pensar não pensava. Não possuía os prazos. Vivi puxando difícil de difícel, peixe vivo no moquém: quem mói no asp’ro, não fantasêia. Mas, agora, feita a folga que me vem, e sem pequenos dessossegos, estou de range rede. E me inventei neste gosto, de especular ideia (ROSA, 1979. p. 10).

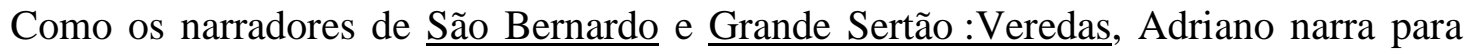
entender melhor sua vida e suas escolhas. Nesse sentido, o fato de optar pela estrutura epistolar também é significativo: seu interlocutor, ao mesmo tempo presente e ausente, à semelhança daquele de Grande Sertão, é quem direciona as opções narrativas, pois Adriano visa, em última instância, repassar a Marco Aurélio, adotado por ele para sucedê-lo, informações que o auxiliarão para o exercício do cargo: “Empenho-me, porém, em instruir-te e também em chocar-te.” (YOURCENAR, 1980. p.29).

Agora vejamos o que diz Yourcenar sobre a narração em 1a. pessoa:

O retrato de uma voz. Se optei por escrever estas Memórias de Adriano na primeira pessoa, foi no sentido de eliminar o máximo possível qualquer intermediário, inclusive eu. Adriano podia falar de sua vida mais firmemente e mais sutilmente do que eu. (YOURCENAR, 1980. p. 300-301).

A autora procura o apagamento de sua pessoa, o que poderia ter como objetivo criar a ilusão de total referencialidade, de respeito estrito ao que 'aconteceu'. Porém, não é isso que vemos na narrativa. Adriano conduz e constrói a estória e a imagem de si e dos outros:

Quando examino minha vida, espanto-me ao encontrá-la informe. A existência dos heróis, tal como nos contam, é simples. Vai direto ao fim como uma seta. [...] Contudo, minha vida tem contornos menos firmes. Como acontece frequentemente, é justamente aquilo que não fui que me define com maior exatidão. [...] A vida obrigou-me sempre a mudar. (YOURCENAR, 1980. p. 32). 
Este excerto aponta uma outra questão citada por estudiosos da ficção de caráter histórico: a diferença entre epopéia e romance. O tempo do epos é o passado absoluto, fechado e inquestionável e seu herói não tem contradições ou conflitos, tem direito e avesso perfeitamente idênticos. O romance, por sua vez, "não comporta heróis, no sentido clássico, mas seres humanos, igualmente capazes de atos heróicos determinados por motivos vis e de ações condenáveis movidas por sentimentos nobres”. (WEINHARDT, 1994. p. 50).

Esta realidade permeia o que é narrado em Memórias de Adriano. O tempo é o século II, bem delimitado, o que aproximaria a narrativa da epopeia. Contudo, Adriano, prioritariamente, e os demais personagens são contraditórios e conflituosos, e a narração é uma tentativa de compreensão do mistério da vida, o que a alinha ao curso do romance:

Sabia que tanto o bem como mal são uma questão de rotina, que o temporário se prolonga, que o exterior se infiltra no interior, e que, com o decorrer do tempo, a máscara se transforma na própria face. [...] A ordem nas fronteiras não valeria nada se eu não persuadisse aquele trapeiro judeu e aquele salsicheiro grego a conviverem tranqüilamente lado a lado. (YOURCENAR, 1980. p. 105).

Aristóteles atribui ao historiador a função de narrar os acontecimentos que realmente sucederam, regidos por uma diversidade aleatória que não se submete ao necessário e ao verossímil. E complementa afirmando que “enquanto a história está circunscrita a relatos de acontecimentos particulares, a poesia se apresenta como anunciadora de verdades mais gerais - universais [...]” (GOBBI, 2004, p. 40).

Adriano também tem sua visão do papel dos poetas e dos historiadores:

Os poetas transportam-nos a um mundo mais vasto ou mais belo, mais ardente ou mais suave, por isso mesmo diferente do nosso e, na prática, quase inabitável.[...] Os historiadores apresentam-nos as imagens do passado através de sistemas excessivamente completos, com uma série de causas e efeitos demasiado exatos e demasiado claros para serem inteiramente verídicos. Recompõem dócil matéria morta, e tenho certeza de que mesmo a Plutarco escapará Alexandre. (YOURCENAR, 1980. p.30).

O contexto sócio-histórico existe sempre como um subtexto, ou um cenário, em cujo « caldo de cultura » o artista se alimenta, mesmo que para tentar negá-lo ficcionalmente. Vale a pena observarmos, ao fazer recortes sincrônicos na história das literaturas nacionais, que mesmo os autores que se sobressaem pelo gênio e maestria, foram «preparados » por autores menores que vivenciaram problemas, sentimentos e acontecimentos semelhantes e os figuraram ficcionalmente cada um à sua maneira. 
Na verdade, esta discussão sobre a relação do poeta e seu contexto nunca saiu de moda e continuará representando uma preocupação constante de todos os que se dedicarem à produção textual, de caráter ficcional ou não, pois a presença do autor nas narrativas cuja preocupação primeira é historiográfica ou jornalística - que se desejam mais próximas do referencial - já é aceita pelos estudiosos, leitores e mesmo pelos próprios autores como algo normal. Mas isso é assunto para um outro estudo.

\section{Conclusão}

O Caderno de Notas, na verdade, poderia ter servido como prefácio. Aí são apresentados os caminhos percorridos e as opções do percurso. Inicialmente, referencia-se a extensão temporal do trabalho (27 anos). Depois, o olhar se volta às opções narrativas e o porquê do interesse pelo imperador Adriano : "Se este homem não tivesse mantido a paz no mundo e renovado a economia do Império, suas felicidades e seus infortúnios interessar-meiam menos”. (YOURCENAR, 1980. p. 304).

E continua explicitando seu fazer poético:

Este livro é condensação de uma obra enorme. Adquiri o hábito de escrever todas as noites, quase automaticamente, o resultado das longas visões provocadas em que eu me instalava na intimidade de um outro tempo. (....) Em certos momentos, aliás pouco numerosos, aconteceu-me sentir que o imperador mentia. Era preciso então deixá-lo mentir, como, de resto, todos nós. (YOURCENAR, 1980. p. 309).

A última passagem é essencial na chave de leitura, que pouco a pouco se nos é dada, desvelando o caráter preponderantemente ficcional da narrativa :

Ignorância daqueles que dizem : “Adriano é você”. Ignorância talvez tão grande como a daqueles que se espantam de que tenha sido escolhido um assunto tão remoto e tão estranho.[...] Em certo sentido, toda vida, quando narrada, é exemplar ; escrevemos para atacar ou para defender um sistema de mundo [...] Nunca perder de vista o gráfico de uma vida humana, que não se compõe, digam o que disserem, de uma horizontal e de duas perpendiculares, mas de três linhas sinuosas, prolongadas até o infinito, incessantemente reaproximadas e divergindo sem cessar : o que o homem julgou ser, o que ele quis ser, e o que ele foi. (YOURCENAR, 1980. p.310).

Yourcenar evidencia nestes dois últimos excertos que, mais do que apresentar o relato « verossímil » de um momento da história da civilização ocidental, sua intenção foi nos apresentar, e deixar registrado, a vida de um homem, singular pelo papel que desempenhou na 
história de Roma, mas singular também enquanto ser humano, que viveu e sofreu, teve suas preferências e escolheu, foi preferido e escolhido, e compôs sua vida no limiar em que todos compomos a nossa.

\footnotetext{
${ }^{1}$ Neste artigo, Gobbi apresenta brevemente as posições teóricas de Platão, Aristóteles, Hegel, Lukács, dos Formalistas Russos, Bakhtin, Roland Barthes, Walter Benjamin e Linda Hutcheon sobre as relações entre ficção e história.
}

\section{Referências}

ANDERSON, Perry. Trajetos de uma forma literária. Novos Estudos, São Paulo, n. 77, p. 205-220, 2007. (CEBRAP)

GOBBI, Márcia Valéria Zamboni. Relações entre ficção e história: uma breve revisão teórica. Itinerários, Araraquara, n. 22, p. 37-57, 2004.

HUTCHEON, Linda. A Poética do pós-modernismo : história, teoria, ficção. Rio de Janeiro: Imago, 1991.

JAMESON, Fredric. O Romance histórico ainda é possível? Novos Estudos, São Paulo, n. 77, p. 185-203, 2007. (CEBRAP)

RAMOS, Graciliano. São Bernardo. São Paulo: Record, Martins, 1975.

ROSA, Guimarães. Grande sertão: veredas. Rio de Janeiro: J. Olympio, 1979.

WEINHARDT, Marilene. Considerações sobre o romance histórico. Revista de Letras, Curitiba, n. 43, p. 49-59, 1994.

YOURCENAR, Marguerite. Memórias de Adriano. Rio de Janeiro: Nova Fronteira, 1980. 